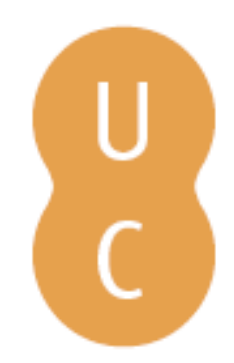

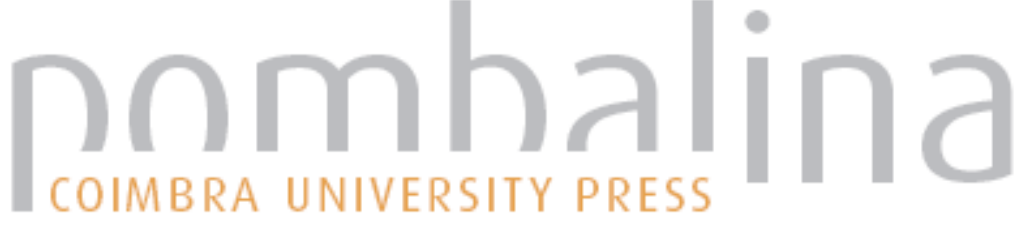

Nuevas perspectivas sobre la compresión auditiva en el aula de E/LE

Autor(es): $\quad$ Martín Peris, Ernesto

Publicado por: Imprensa da Universidade de Coimbra

URL

persistente: URI:http://hdl.handle.net/10316.2/41009

DOI: $\quad$ DOI:http://dx.doi.org/10.14195/978989261231-7_6

Accessed : $\quad$ 26-Apr-2023 09:19:47

A navegação consulta e descarregamento dos títulos inseridos nas Bibliotecas Digitais UC Digitalis, UC Pombalina e UC Impactum, pressupõem a aceitação plena e sem reservas dos Termos e Condições de Uso destas Bibliotecas Digitais, disponíveis em https://digitalis.uc.pt/pt-pt/termos.

Conforme exposto nos referidos Termos e Condições de Uso, o descarregamento de títulos de acesso restrito requer uma licença válida de autorização devendo o utilizador aceder ao(s) documento(s) a partir de um endereço de IP da instituição detentora da supramencionada licença.

Ao utilizador é apenas permitido o descarregamento para uso pessoal, pelo que o emprego do(s) título(s) descarregado(s) para outro fim, designadamente comercial, carece de autorização do respetivo autor ou editor da obra.

Na medida em que todas as obras da UC Digitalis se encontram protegidas pelo Código do Direito de Autor e Direitos Conexos e demais legislação aplicável, toda a cópia, parcial ou total, deste documento, nos casos em que é legalmente admitida, deverá conter ou fazer-se acompanhar por este aviso.

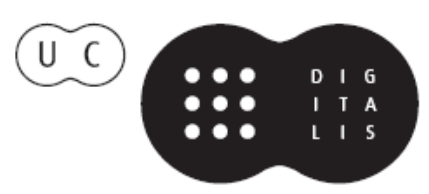




\section{ENSEÑAR ESPAÑOL EN LA ACTUALIDAD \\ CONTRIBUCIONES DIDÁCTICAS}

MARÍA LUISA' AZNAR JUAN ELENA GAMAZO CARRETERO II.

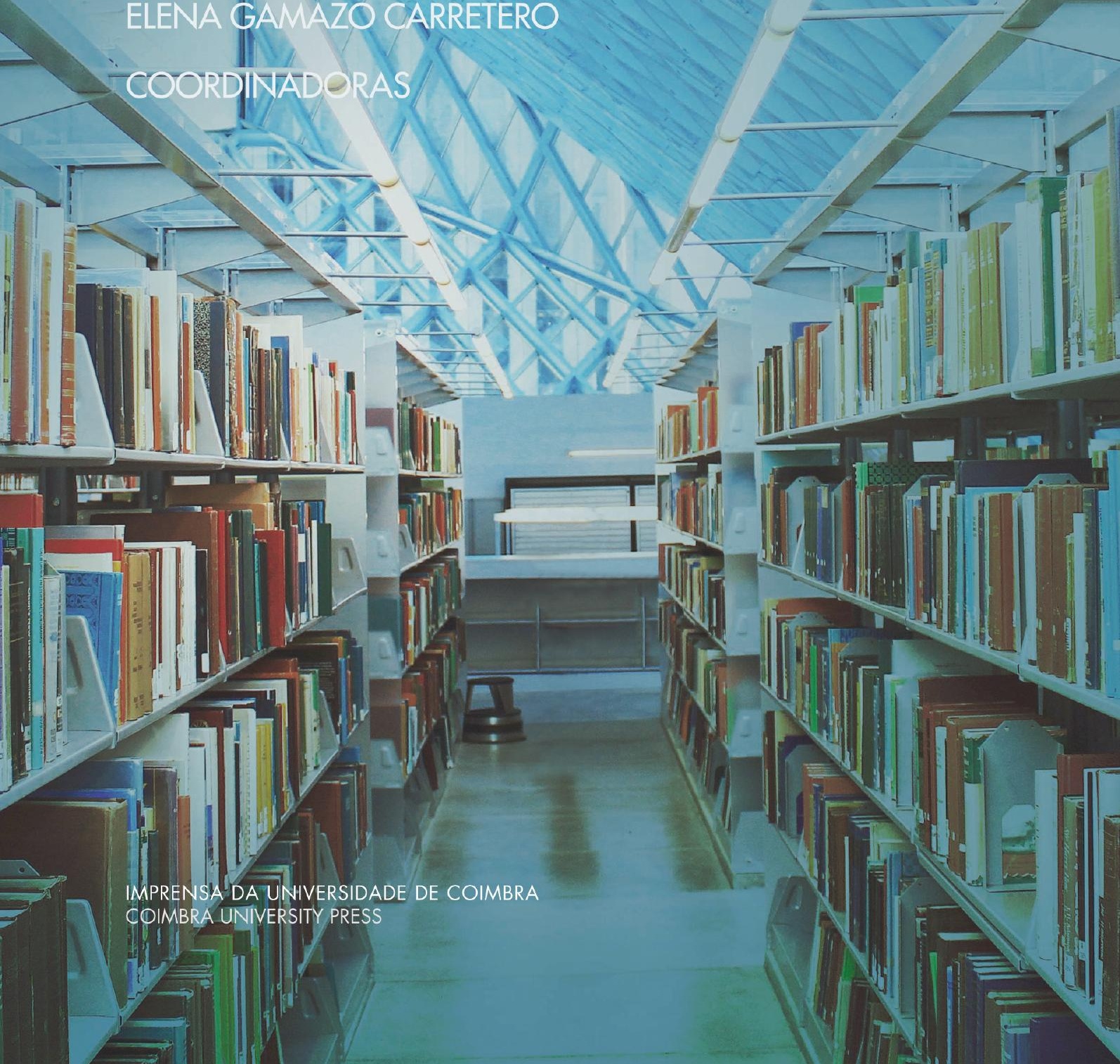




\title{
NUEVAS PERSPECTIVAS SOBRE LA COMPRESIÓN AUDITIVA EN \\ EL AULA DE E/LE
}

Ernesto Martín Peris

Universitat Pompeu Fabra (Barcelona)

\begin{abstract}
Drawing from a point of view which is based on the idea that the innovations are always built on the basis of experience and expertise, this article underlines two work streams that provide a new dimension in teaching listening comprehension: its connection to discursive genres and critical literacy, both notions directly linked to the need for an increased number of critical users of the language.
\end{abstract}

Keywords: E/LE teaching, discourse genres, critical literacy, listening comprebension.

\section{RESUMEN}

Partiendo de una perspectiva en la que las innovaciones se construyen siempre sobre la base de la experiencia y los conocimientos acumulados, en este texto se subrayan dos líneas de trabajo que 
aportan una nueva dimensión a la didáctica de la comprensión auditiva: su relación con los géneros discursivos y la literacidad crítica, conceptos directamente relacionados con la necesidad de fomentar usuarios críticos de las lenguas.

Palabras clave: enseñanza de E/LE, géneros discursivos, literacidad crítica, compresión auditiva.

\section{INTRODUCCIÓN}

\section{LO NUEVO Y LO VIEJO EN LA DIDÁCTICA : INNOVACIÓN Y CONTINUIDAD}

En la didáctica de segundas lenguas (y en sus distintas áreas) se produce una continua ampliación de la perspectiva, así como una profundización en la explicación de los fenómenos y procedimientos que en ella se dan. El área de la comprensión de mensajes orales no escapa a esta dinámica.

Interesa destacar aquí que en demasiadas ocasiones se tiene la impresión de que las nuevas orientaciones se presentan como si fueran contrapuestas a las ya asentadas y con que se venía trabajando. En realidad, para que tenga lugar un verdadero progreso es importante seguir construyendo sobre lo ya heredado, beneficiándose así de la experiencia y conocimientos acumulados e integrándose en la corriente de personas, círculos e instituciones que han venido promoviendo una mejora constante de la actividad de la enseñanza. Ello no obstará, lógicamente, al abandono de puntos de vista o procedimientos de trabajo que se revelen claramente superados u obsoletos.

En este texto aspiramos a integrarnos en esa corriente de continuidad e innovación; asumimos, por tanto, todos los logros que se han dado en el desarrollo de la didáctica de la comprensión auditiva 
y nos proponemos reflexionar sobre los nuevos aspectos que a esa didáctica pueden aportar dos líneas de estudio que se están revelando muy poderosas y fructíferas, al tiempo que estrechamente relacionadas entre sí. La primera de estas líneas pertenece al campo de las ciencias del lenguaje y atiende a la naturaleza de la lengua, que se plasma siempre en unos determinados géneros discursivos; la segunda, a las necesidades de aprendizaje de lenguas en el mundo actual, y más en particular a la necesidad de fomentar el desarrollo de usuarios críticos de las lenguas; es lo que se ha dado en llamar literacidad crítica.

Los géneros discursivos son formas históricamente evolucionadas (y en permanente evolución) del uso social del lenguaje. Desde el punto de vista de su estudio, la crítica literaria tradicional había ya identificado un conjunto de géneros y subgéneros, cuyas características y propiedades había definido exhaustivamente (tales como la novela, el cuento, el relato breve, la tragedia, la comedia, el sainete...); con unos siglos de antelación, la retórica clásica había establecido también una clasificación de géneros del discurso público (el judicial, el deliberativo y el demostrativo).

Lo peculiar de los nuevos estudios de los géneros discursivos (Bajtín, 1979; Swales, 1990) ${ }^{1}$ es que se aplican a todos los usos actuales de la lengua y no únicamente a los literarios o a los de la vida pública; atienden por igual, por tanto, a los géneros que se dan en las relaciones personales y cotidianas como a aquellos otros que aparecen en esferas especializadas de la actividad humana; incluyen el estudio de los géneros de la lengua oral junto a los de la lengua escrita. Estos géneros se definen pragmáticamente por los parámetros externos al texto más que por las características intrínsecas de este; es decir, por el contexto social de comunicación en que se originan, por

1 También puede consultarse provechosamente Martín Peris (Dir.), (2008), así como la excelente obra de Calsamiglia, H. \& Tusón, A. (2007). Las cosas del decir. Manual de análisis del discurso. Barcelona: Ariel Lingüística. 
los correspondientes roles sociales que asumen los interlocutores, por su relación entre sí y por la que mantienen hacia el tema del texto, etc.

En cuanto a los estudios de literacidad crítica, que originalmente contemplaban únicamente la lengua escrita, conviene destacar que sus análisis, sus explicaciones y sus propuestas son perfectamente extrapolables a la comunicación oral. En ellos se hace más hincapié en la recepción de textos que en su producción, pero las habilidades de expresión se incluyen también entre las condiciones de activación de una competencia crítica. El término de "literacidad crítica" se propone como una alternativa al de "alfabetización" (y su correlativo, "analfabetismo"), para referirse a la capacidad de desenvolverse eficazmente en el uso crítico de los diversos discursos en que se ve inmerso el ciudadano de las modernas sociedades avanzadas y que van más allá de la capacidad de reconocer el mensaje de un texto y de hacer inferencias sobre su contenido no explícito. En expresión de Daniel Cassany, se trata no solo de ser capaz de leer textos sabiendo "leer entre líneas", sino de saber "leer tras las líneas"; es decir, de reconocer la función y el valor social de un determinado discurso, activando para ello un abanico de conocimientos, habilidades, puntos de vista, valores y actitudes.

\section{Relevancia de las nuevas perspectivas para la didáctica de la compresión auditiva}

Los planteamientos de los estudios de los géneros discursivos y de la literacidad crítica resultan especialmente apropiados para una didáctica de las lenguas que tiene una de sus principales fuentes de inspiración en el Marco Común Europeo de Referencia del Consejo de Europa y, en el caso del español, en el Plan Curricular del Instituto Cervantes. Ambos documentos abogan por un "enfoque orientado 
a la acción", en el cual el alumno se concibe como un "usuario de la lengua" que, en cuanto "agente social", participa en diferentes prácticas discursivas sociales. Ello quiere decir que el uso de los textos en el que un alumno se ejercita al llevar a cabo sus actividades de aprendizaje (así como el uso de textos que realiza en su vida social presente o realizará en la futura) no consiste en una acción individual y aislada, desligada de su entorno actual, sino en una interacción social, es decir, en una forma de actuar (mediante el uso de la lengua) que no puede concebirse ni realizarse al margen de unas condiciones sociales, tanto momentáneas como sociohistóricas, que la determinan en su forma y en sus procesos; de hecho, los estudios sobre el aprendizaje han puesto de relieve cómo la interacción social es el verdadero motor del aprendizaje, tanto si se trata del aprendizaje de lenguas como de cualquier otro aprendizaje, tanto del aprendizaje de la primera lengua como del de una segunda o de las sucesivas, ya se produzcan estos fuera del aula, ya sea dentro de ella. En esa participación en prácticas discursivas sociales, el "alumno-usuario" recurre a un conjunto de competencias que ya posee, y que desarrolla y enriquece en su proceso de aprendizaje: tradicionalmente se había hablado de la competencia comunicativa como aquella que facilita el uso eficaz y adecuado de la lengua; el Marco Europeo sitúa esta "competencia comunicativa" entre otras que la persona posee y desarrolla, a las que llama "competencias generales" y que especifica en estas cuatro: "saber", "saber hacer", "saber aprender" y "saber ser". Nos interesa destacar esta última, que otros autores llaman la "competencia existencial" (Van Lier, 1996) y que no es otra cosa que la capacidad de representar mediante el uso del lenguaje el conjunto de actitudes y valores que toda persona posee y a las que se alude en la teoría de la literacidad crítica. Destaquemos también que la dimensión social del lenguaje se asocia de manera preeminente a la existencia de los géneros discursivos, propios de una sociedad 
en un momento particular de su evolución histórica. Nos detendremos en estos aspectos en los dos apartados siguientes.

\section{Los géneros del discurso y la competencia auditiva}

Hace cincuenta años la gente escribía y recibía cartas: cartas familiares, cartas comerciales, cartas circulares, etc. Hoy seguimos haciéndolo; pero si comparamos las cartas de hace cincuenta años con las de la actualidad, veremos que en su estructura, en sus expresiones, en su vocabulario, son muchas las cosas que han cambiado. Si apartamos ahora nuestra mirada del interior de las cartas y la dirigimos al contexto externo a ellas en el que aparecen, veremos que también han cambiado muchas cosas. Para abreviar con un ejemplo: mensualmente llega a la mayor parte de los actuales hogares una cantidad variable de cartas a las que sus destinatarios prestan una atención diferente según los casos; entre ellas hay cartas con publicidad comercial, con ofertas especiales, con escritos de las entidades bancarias que acompañan los informes de movimientos en las cuentas... Imaginemos que hace cincuenta años una familia hubiera recibido una de esas cartas en las que se nos dice que hemos ganado no sé qué premio, con la única condición de asistir a una determinada reunión en tal y tal fecha y lugar... Algunos hubieran corrido como locos a la cita; otros, más precavidos, tal vez al despacho de un notario. En la actualidad, probablemente más de la mitad de esas cartas van directamente a la papelera: los usuarios han identificado de inmediato su función (de propaganda o publicidad) y, muy probablemente, también su contenido, y las desechan sin más porque no les interesan; si, por el contrario, el envío postal llega con acuse de recibo, el destinatario se maliciará que contiene alguna noticia poco grata y que, además, muy probablemente reclamará de él alguna acción (como por ejemplo, el aviso de una sanción de 
tráfico o la cita a una sesión de un tribunal). Lo mismo cabría decir de las llamadas telefónicas que suelen recibir quienes pasan una jornada trabajando en su casa y disponen de línea telefónica fija; desde las primeras palabras audibles en el auricular, será posible en muchos casos reconocer el tipo de llamada que se está recibiendo y reaccionar adecuadamente ${ }^{2}$. De forma análoga, hace cincuenta años la comunicación urgente se hacía mediante telegramas y hoy se hace mediante correos electrónicos. Pero, de nuevo aquí, tanto la estructura interna de los mensajes como la función que cumplen, la respuesta que provocan, etc., han variado enormemente.

Tanto el espacio público en el que nos movemos como los círculos personales a los que pertenecemos poseen actualmente una gran cantidad de géneros textuales que antes no existían, algunos de los que existían han desaparecido y otros se han transformado. Los cambios experimentados por estos géneros son variados y diversos, y no podemos detenernos aquí en un análisis detallado; fijaremos, pues, someramente nuestra atención en uno de estos cambios, a saber, la proliferación de discursos en soporte audiovisual y la combinación de distintos códigos que en ellos se da: por un lado, el código icónico (las imágenes y los distintos recursos ortotipográficos; y, entre las imágenes, habrá muy probablemente otros códigos, como el del vestuario, la disposición, etc. ${ }^{3}$ ); por otro, la combinación de textos en lengua oral y en lengua escrita. La comunicación humana es siempre multimodal, el lenguaje como sistema semiótico se utiliza siempre inserto en un marco más amplio que incluye otros sistemas; los nuevos géneros recogen de manera creciente esta multimodalidad.

\footnotetext{
${ }^{2}$ Aquí, a diferencia de lo que sucede con los sobres que van directamente a la papelera sin haber sido abiertos, el paciente receptor de la llamada se ve en la necesidad de desarrollar una estrategia, más o menos cortés a tenor del grado de impaciencia que la importuna llamada le haya provocado, para colgar cuanto antes el auricular del teléfono.

${ }^{3}$ En relación con la comprensión crítica de la imagen puede consultarse «El discurso de la mirada crítica», de E. Atienza Cerezo \& C. López Ferrero, en Cassany (2009: 191-207).
} 
Podemos comprobarlo diariamente en programas de televisión, en películas de cine, en contenidos de Internet, incluso en escenarios de música y de teatro, en los que el subtitulado o la proyección de textos escritos se integran en un discurso complejo y global.

Todo ello nos obliga a considerar de nuevo la comprensión auditiva como una actividad que se desarrolla inserta en una comprensión más global del discurso. Todo lo que se ha venido estudiando hasta el momento en relación con esta habilidad o destreza (que ahora se prefiere denominar "actividad de comunicación") sigue teniendo su validez: la importancia de los conocimientos previos, la atención a la relación entre los interlocutores, la adecuada interpretación de las expresiones lingüísticas, tanto en su base léxica y morfosintáctica como en sus características prosódicas, la entonación y los matices expresivos, etc. Pero todo esto debe integrarse en un marco más amplio, que muchas veces incluye imagen y texto escrito, cuya aportación al mensaje global también es necesario saber interpretar ${ }^{4}$.

Si nos detenemos ahora a considerar las características de la lengua oral en sí misma, veremos que algunas de ellas pueden estudiarse en paralelo con las de la lengua escrita. A este respecto es interesante la concepción de la oralidad y de la escritura que presentan Koch \& Oesterreicher (2007). Proponen estos autores un doble plano en la consideración de estas dos manifestaciones de la lengua: el plano del canal y el del modo. Desde el punto de vista del canal, puede afirmarse que el emisor ha de realizar una opción por el canal oral o por el gráfico, cada uno de los cuales posee rasgos propios, tanto en las unidades de emisión (fonemas, alófonos, tonemas, pausas, ritmo... frente a grafemas, tipo y cuerpo de los caracteres,

${ }^{4}$ Uno de los escasos reductos en los que resulta imposible la combinación audiovisual es la radio; en ella (y mientras siga siendo radio) no cabe la imagen, únicamente los sonidos y la voz (también, claro, el silencio). 
manuscritos o tipografiados, subrayados y mayúsculas, disposición en la página, etc.), como en el otro nivel de articulación de la lengua, especialmente en la sintaxis y el léxico; características, todas estas, que han sido ampliamente descritas en los estudios de lingüística. Desde el punto de vista del modo, estos autores proponen para el modo oral y el modo escrito un contínuum comunicativo en una escala de proximidad-distancia, con rasgos compartidos por los dos modos. A la ubicación de un particular intercambio comunicativo en un punto determinado de esta escala (tanto en el modo oral como en el escrito, como en una combinación de ambos) contribuyen unas condiciones que Koch y Oesterreicher (2007) definen con los siguientes binomios de parámetros: privacidad-publicidad, intimidaddistancia afectiva, mayor o menor implicación emocional, mayor o menor vinculación a la situación de comunicación, proximidad o distancia físicas, diálogo-monólogo, espontaneidad-reflexión y tema fijo o tema libre. A estas condiciones dadas hay que sumar unas estrategias de los interlocutores: el recurso al lenguaje verbal o la incorporación de los no verbales, la escasez de la planificación frente a un esfuerzo por realizarla, o el carácter provisional o definitivo del mensaje, por ejemplo.

Así, podría ejemplificarse esta escala de proximidad-distancia comunicativa en sendas listas de géneros, del canal fónico y del canal gráfico. En el primero, el grado de máxima proximidad correspondería a una conversación privada en presencia de los interlocutores, y se iría alejando progresivamente en los siguientes hitos: en una conversación por teléfono, en una entrevista periodística, en una entrevista de selección de personal, en un sermón en una iglesia y en una conferencia en un congreso. En el canal gráfico, el extremo de la mayor distancia podría estar representado por un tratado científico, y el progreso hacia la proximidad trascurriría a través de un comunicado oficial, una información de prensa, una carta personal, un $e$-mail particular y un post-it privado. 
Tanto en un canal como en el otro, los interlocutores han de tomar una serie de opciones relativas a distintos componentes del texto. Uno de ellos es el registro: elevado, cuidado, informal, vulgar, etc. otro es el estrato o nivel social: lenguaje popular, juvenil, especializado de un área de actividad social o profesional, etc. También, las variedades locales, repartidas estas por zonas geográficas de un país, urbanas o rurales, de barrios o comarcas, etc. Todas estas opciones se manifestarán en la adecuada elección de unidades pertenecientes a los diversos niveles de descripción de la lengua (la pronunciación, el vocabulario, la morfosintaxis) y a la retórica, o la forma de combinarse estas formas en una secuencia textual. Veamos un ejemplo concreto en el siguiente mensaje transmitido por correo electrónico 5 :

From: "Carlota Gil"<cgil01@nu.org>

To: "Dolores Muñoz"<dolores.munoz@cup.edu>

Sent: Friday, March 03, 2007 10:55 AM

Subject: Saludos

Ay, Lolita, por fin te escribo... Discúlpame, que lo dejé para el día siguiente y por poco pasa un mes... Es que yo, al contrario que tú, tengo más clases y más rollos varios en este último trimestre $\because$ [...].

Nosotros estuvimos de viaje en Navidad, pero tuvimos la mala suerte de que Ricardo tuvo un bajonazo gordo justo antes de salir, así que los primeros dos días no disfrutamos tanto. Ahora empieza a encontrarse mejor ya.

Te mando un fuerte abrazo y saludos de las compañeras (y de los chicos que andan por aquí, que están muy contentos con tus notas).

Cuídate mucho,

Carlota.

Dpto. de Historia Contemporánea. Universidad Nueva.

5 Este documento es la reproducción de un mensaje de correo electrónico real, en el que se han realizado únicamente las modificaciones necesarias para preservar su anonimato. 
Hemos elegido este documento porque ilustra muy bien varios de los puntos que nos interesa resaltar en este trabajo ${ }^{6}$ : En primer lugar, la emergencia de un nuevo género textual (el del correo electrónico), que se inserta en una tradición comunicativa y cultural determinada (el de la comunicación epistolar, con cartas, telegramas, tarjetas postales, etc.) y de la cual extrae muchos elementos que conserva en su formato y estructura; también, la presencia en un texto escrito de recursos habitualmente tratados como propios de la lengua oral coloquial; la importancia de los recursos tipográficos e icónicos que pueden observarse en el texto, etc. Enumeraremos sucintamente algunos de estos rasgos:

- El saludo. Por ser un género emergente y aún no consolidado, los interlocutores del correo electrónico vacilan mucho a la hora de iniciar el texto. Muchos de ellos adoptan directamente el saludo oral coloquial ("Hola"), pero nadie o casi nadie adopta el de las cartas ("Querida amiga"), salvo que confieran al $e$-mail el carácter de una carta. Esta autora ha optado por un recurso muy propio también de la lengua oral, que consiste en dirigirse al interlocutor con su nombre de pila.

- El icono de la carita sonriente o triste. El hecho de que este icono, con sus diversas variantes, nos venga facilitado por las actuales herramientas informáticas no debe confundirnos respecto de la importancia de su aparición: otros recursos igualmente disponibles gracias a la informática no entran (de momento) en este género. Obsérvese que se trata de una comunicación informal

\footnotetext{
${ }^{6}$ Lo hemos elegido también porque, siendo un texto del canal gráfico, nos permite presentar y comentar más fácilmente las características que nos interesan. Estos comentarios serán perfectamente extrapolables a textos orales análogos (como, por ejemplo, los mensajes de voz en el teléfono). Hay que tener presente, además, que las tecnologías de la información y la comunicación, en su permanente desarrollo, están propiciando la emergencia de nuevas prácticas comunicativas en las que la multimodalidad a que hemos hecho alusión más arriba incrementa su presencia.
} 
entre dos profesoras de universidad: hace cincuenta años, ni siquiera en una carta escrita a mano hubieran recurrido estas personas a códigos icónicos para completar su mensaje, aunque tuvieran medios para hacerlo; solo las adolescentes (pero no los varones) solían adornar su correspondencia con dibujitos y colorines. Hoy eso ha cambiado y (si el contexto nos lo permite) no nos privamos de incluir un icono que matiza de forma eficaz el contenido de nuestro mensaje (de manera aproximada a como lo haría una particular entonación de la voz o un gesto que acompañara la palabra), al tiempo que nos ahorra el esfuerzo de tener que expresar ese matiz con una larga frase.

- El vocabulario y la sintaxis elegida. Contienen estos diversas unidades muy frecuentes en la lengua oral conversacional: "por poco pasa un mes", "rollos varios", "tuvo un bajonazo gordo", etc.

Vemos, pues, en este ejemplo cómo la línea divisoria entre lengua oral y lengua escrita se debilita en determinados géneros y cómo, a la inversa, podremos encontrar géneros en el canal oral que se situarán en un punto de la escala más próximo al extremo de la distancia comunicativa. De hecho, en este campo han surgido interesantes aportaciones con el concepto de géneros mixtos. Munby $(1981)^{7}$, por ejemplo, propone una tipología en la que aparecen "monólogos hablados para ser escuchados» (una conferencia) o "para ser escritos" (un dictado) junto a "monólogos escritos para ser leídos" (vale decir para ser leídos como escritos: un periódico) o "como si fueran escuchados" (una novela); o bien, «monólogos escritos para ser dichos» (ser dichos como textos escritos y no como textos orales: un noticiario televisivo; o ser dichos como si

7 En Cassany, D. (1994). Enseñar Lengua. Barcelona: Graó, p. 94. 
no estuvieran escritos: el teatro). Para los diálogos, Munby ofrece una taxonomía análoga a la de los monólogos.

\section{Las prácticas discursivas sociales}

Como habíamos señalado, las particularidades de un determinado texto (en nuestro caso concreto, un texto que un estudiante extranjero ha de llegar a conocer y dominar, si desea intervenir en la interacción social de forma efectiva y eficaz mediante el uso de ese texto) vienen determinadas, en gran medida, por el género textual al que pertenece. Para ilustrar este principio tomemos un tema cualquiera, por ejemplo "la subida del coste de la vida", y veamos en cuántos géneros distintos puede abordarse:

- Una tertulia de sobremesa.

- Una carta abierta individual a la prensa.

- Una negociación sindical.

- Un debate en el Parlamento.

- Una tertulia en la radio.

- Un discurso en un mitin.

- Un manifiesto colectivo publicado en los medios de comunicación.

- Una sesión de un seminario universitario de Económicas.

- Una manifestación de vecinos en la calle.

- Etc.

En cada uno de estos actos de comunicación aparecerán distintas funciones lingüísticas:

- En la tertulia de sobremesa los participantes se lamentarán, harán comentarios críticos, contarán chistes o anécdotas, 
corroborarán o desmentirán informaciones de otros, citarán opiniones de ausentes, etc.

- En la negociación sindical, exigirán cosas, harán propuestas, definirán condiciones, llegarán a acuerdos...

- En la tertulia de la radio se darán explicaciones, se expondrán razonamientos, se pondrán ejemplos, se relatarán casos.

- Etc.

Pero, además, cada una de las prácticas anteriores posee reglas propias de participación:

- Distintas reglas de intervención: por turnos acordados, sin orden previo, etc.

- Distintas jerarquías de intervención: con moderador o sin él, con autoridades reconocidas (edad, estatus, especialización) o sin ellas, etc.

- Distintas reglas de interacción: interrumpir libremente, esperar a que termine la intervención anterior, pedir la vez, etc.

- Distintas reglas de cortesía: desautorizar abiertamente, criticar veladamente, etc.

- Distinto tratamiento de los interlocutores (y haciéndolo en simetría o disimétricamente): tuteo, usted respetuoso, usted solemne...

- Distinto vocabulario: objetivo, emotivo, técnico, popular...

- Distintas estructuras sintácticas: mayor o menor proximidad a la prosa escrita, a la gramática oracional.

- Distintas mímica, gestualidad y posturas; distinta situación en el espacio físico.

- Distintos recursos a otros códigos: vestimenta, objetos.

- Etc. 


\section{El tratamiento de los génetos discursivos en la didáctica de la compresión auditiva}

En relación con todo lo anterior, podemos formularnos algunas preguntas que resultan cruciales para el tratamiento de los géneros en el aula de E/LE:

- ¿Cómo se entiende la idea de "participación" del alumno en esas prácticas sociales de uso de la lengua?

- ¿Cómo influye en las actividades que se realizan en el aula esa comprensión de la participación del alumno?

- ¿Cómo influye en la previa selección de textos que el profesor realiza para sus clases (o los autores de los materiales para sus libros)?

- ¿Cómo insertamos esos textos audio(visuales) en la secuencia didáctica?

- ¿Qué formas de participación de los alumnos proponemos?

- ¿En qué medida tomamos en consideración el Yo del alumno para que pueda participar de forma plena, verídica, autónoma y crítica en esas prácticas?

Las respuestas relativas a la participación del alumno en las prácticas de comprensión auditiva deberían atenerse, a nuestro entender, a unos criterios apropiados a la siguiente tipología de actividades de comprensión:

a) Comprensión de mensajes en una interacción bidireccional o multidireccional, en reciprocidad de los interlocutores; por lo tanto, producción y recepción imbricadas en una misma actividad. Dentro de ella, el alumno intervendrá siempre como miembro participante del evento (tertulia, conversación, entrevista, etc.). 
b) Comprensión de mensajes en una interacción unidireccional; por tanto, con solo participación receptiva. El alumno podrá intervenir en una de estas dos condiciones:

1. Como miembro participante del evento (en instrucciones y avisos públicos, por megafonía u otros medios, en programas de radio o televisión, etc.).

2. Como observador de una escena externa a él (en obras de ficción en la televisión, la radio, el cine, el teatro...).

c) En ambos casos, la participación contribuirá al desarrollo de la capacidad de uso de los diferentes sistemas semióticos usados en el evento, y ello tanto para la producción de mensajes como para su interpretación.

\section{La literacidad crítica y la compresión auditiva}

La literacidad crítica se enmarca en un nuevo paradigma educativo (McLaren \& Kincheloe, 2008), que bebe en las fuentes del análisis crítico del discurso (Fairclough, 1995; Van Dijk, 1999) y de la teoría sociocultural del aprendizaje (Van Lier, 1996). J. M. Cots (2006) presenta este paradigma en contraposición a un modelo heredado, cuyas limitaciones pretende superar. Este modelo heredado, que Cots califica de individualizador, se caracteriza por fijarse como objetivo de la educación la preparación para la vida adulta, mediante el desarrollo de las competencias de un ciudadano productivo (entre las que destaca la capacidad de actuar socialmente del modo más eficaz y apropiado), en el que la norma de actuación se presenta como una opción de la persona y no como una imposición arbitraria sobre ella. El modelo alternativo propone un aprendizaje de por vida, realizado mediante el desarrollo de habilidades que le permitan al 
individuo, entre otras cosas, reaccionar ante lo nuevo e inesperado, adoptar decisiones personales con conocimiento de causa, construir conocimientos útiles en interacción con el propio entorno y guiarse por valores, convicciones y razones personales.

Daniel Cassany (2006), por su parte, describe del siguiente modo a la persona dotada de capacidades discursivas críticas:

a) Comprende de forma autónoma el propósito lingüístico, las intenciones pragmáticas y los puntos de vista que subyacen a los discursos que la rodean.

b) Toma conciencia del contexto (contenido cognitivo, género discursivo, comunidad de hablantes, etc.) desde el que se han elaborado esos discursos.

c) Puede construir discursos alternativos, que defiendan sus posiciones personales y que se vinculen polifónica o intertextualmente con los anteriores.

d) Utiliza todos los recursos lingüísticos disponibles para conseguir representar discursivamente sus opiniones a través de esos segundos discursos.

Se ha hablado antes de la pluralidad y diversidad de discursos que se dirigen a los ciudadanos de las modernas sociedades avanzadas; se ha comentado la evolución que es característica intrínseca de los géneros discursivos, así como su pertenencia a una determinada sociedad, con sus peculiaridades sociohistóricas; se ha insistido en la interrelación bidireccional entre una determinada sociedad y los géneros que en ella surgen. Todo ello nos lleva directamente a la necesidad de interrogarnos por las formas más eficaces de práctica didáctica de la comprensión auditiva, para que los alumnos de cursos de lenguas extranjeras puedan desenvolverse de forma eficaz y adecuada en cuanto agentes sociales que interpretan adecuadamente esos discursos, lo que hay en ellos y lo que hay tras ellos, 
y puedan reaccionar de forma apropiada, autónoma y crítica a esa interpretación. Tales prácticas pasan, como recoge la caracterización de la persona crítica de Daniel Cassany que acabamos de citar, por el reconocimiento del particular género discursivo y de las normas a que se atiene; pensemos, por ejemplo, en la publicidad, tanto en la comercial como en la política e ideológica, y en el valor que en nuestro mundo actual podemos adjudicar a sus aseveraciones, a sus promesas, a sus compromisos. Pensemos, también, en la información (de todo tipo: cultural, política, social...) y en los grupos de poder que la monopolizan y la difunden a través de los medios. Pensemos, igualmente, en los múltiples contenidos que circulan por Internet y en la necesidad de formar a los jóvenes en un uso crítico y eficaz de este medio.

No perdamos de vista que estas consideraciones sobre la recepción crítica se aplican igualmente a la comunicación privada, a los mensajes orales que se producen en el ámbito de las relaciones sociales, familiares o profesionales: también en ellos es necesario entender lo que hay "tras las líneas" y ser capaz de reaccionar de forma autónoma y crítica a lo interpretado.

\section{Una muestra de las posibles aplicaciones prácticas}

Como muestra de un posible procedimiento didáctico para incorporar a la práctica de la comprensión auditiva estas nuevas perspectivas, tomaremos el documento audiovisual "Lo que toca en Navidad"; corresponde a un anuncio de la Lotería Nacional que fue emitido en España por televisión y en los cines en las Navidades de hace un par de años. Se trata de un documento que representa a la perfección uno de estos nuevos géneros a los que nos venimos refiriendo y que contiene multimodalidad de códigos en alto grado. 


\subsection{El guión del anuncio}

En un artículo impreso no es posible presentar el documento audiovisual, lo que permitiría apreciarlo en toda su complejidad de códigos $^{8}$. En su defecto, transcribimos el texto que recita una voz en off, lo que deberá constituir base suficiente para nuestros comentarios. Es como sigue:

\section{Lo que toca en Navidad}

¿Qué es lo que toca en Navidad?

Toca viajar... reencontrarse... recordar... regalar.

Toca tocar la nieve.

Toca besar... y bailar.

Toca pasar un poco de frío.

Toca la orquesta sinfónica.

Toca pedir lo imposible.

Toca compartir.

Y toca jugar a la lotería.

Lotería de Navidad.

Es lo que toca.

\subsection{La explotación didáctica}

Además de las habituales actividades con las que solemos practicar el desarrollo de la comprensión auditiva, para abordar el trabajo con este documento podemos partir del género discursivo reconocible y de su función social; se trata, en efecto, de un anuncio publicitario de una entidad cuasi institucional, que se inscribe en un marco cultural compartido por la gran mayoría

\footnotetext{
${ }^{8} \mathrm{El}$ anuncio es accesible en esta dirección: http://www.youtube.com/watch?v=42zjVAPslrM.
} 
de la población española: la costumbre social de jugar a la lotería por Navidad (en muchas ocasiones de forma colectiva, en grupos de compañeros de trabajo, de parientes, etc.).

Incorporaremos, también, elementos del análisis crítico del discurso en la comprensión y comentario de los contenidos de diverso orden (lingüísticos, culturales, etc.). Integraremos, pues, los distintos niveles:

- La práctica social: campaña publicitaria de Navidad.

- El documento audiovisual y los diversos códigos que utiliza:

- Texto lingüístico recitado oralmente.

- Imágenes, su secuencia y su relación con el texto.

- Otros elementos sonoros (especialmente musicales).

- El contenido del mensaje y la ideología que contiene y transmite.

En relación con la práctica social en que se inscribe el documento y el género que representa, podremos plantear a los alumnos preguntas como las siguientes:

- ¿Cuándo crees que se emite este anuncio? ¿Dónde? ¿En qué basas tu respuesta?

- ¿Quién lo emite? ¿A quién lo dirige? ¿Con qué fin?

- ¿Qué otros anuncios suelen emitirse en esos lugares y en esas fechas?

- ¿Van todos esos anuncios en una misma dirección? ¿Son contrapuestos entre sí?

- ¿Podrían o deberían hacerse otras campañas diferentes? ¿Con qué fin?

Para la comprensión crítica del mensaje podremos valernos de preguntas relacionadas con estos temas:

- ¿Con qué otras prácticas e ideas asocia el anuncio la de jugar a la lotería? 
- ¿Con qué recursos lingüísticos consigue esa asociación?

- ¿Qué elementos de otros códigos (música, imágenes) refuerzan esos recursos lingüísticos?

- ¿Presenta esas prácticas e ideas como experiencias y valores positivos, neutros o negativos? ¿Agradables o desagradables?

- ¿Cuáles de ellos percibís tú y tus compañeros de la misma forma que el autor (positivos, neutros o negativos, agradables o desagradables)?

- ¿Cómo trata de convencernos de que hagamos lo que nos invita a hacer?

- ¿Te parece que para ello utiliza un tono autoritario, sugerente, cómplice...?

- ¿Qué dirías tú si estuvieras en su lugar?

- ¿Qué conocimientos (no lingüísticos) te faltan sobre la sociedad en que surge este anuncio, para poder comprenderlo en todas sus dimensiones??

Podemos finalizar el trabajo proponiendo a la clase una tarea como esta:

- Discutiremos en pequeños grupos los siguientes puntos, y trataremos de lograr un acuerdo al respecto:

- "Es lo que toca": ¿Qué nos transmite esta expresión: una sugerencia, una obligación, un compromiso...?

- ¿Por qué "toca besar" o "regalar" en Navidad? ¿o "pedir lo imposible"?

9 Una de las habilidades importantes en el aprendizaje de una nueva lengua es la de reconocer las propias limitaciones y carencias en su uso. Muchas veces, como sabemos, estas provienen no tanto del desconocimiento de la gramática o el vocabulario cuanto del de otros componentes fundamentales de la comunicación, especialmente pero no únicamente - de orden sociocultural; por ello resulta importante introducir frecuentemente reflexiones como la que contiene esta última pregunta. 
- ¿En tu país o en tu círculo de relaciones, también toca hacer esas cosas en Navidad? ¿Qué otras cosas considera la gente de tu país que "toca hacer en Navidad"?

- ¿Qué es lo que - de verdad - toca hacer según el anuncio?

- ¿Qué efectos crees que produce la difusión de este anuncio en la sociedad a la que va destinado y en sus distintos grupos (los jóvenes, los jubilados, los profesionales, etc.)? ¿Qué valores o actitudes refuerza, cuáles debilita...?

- ¿Cómo crees que influye en el comportamiento de la gente? ¿Cómo crees que influiría en tu sociedad?

- ¿Qué otros discursos podemos encontrar semejantes a este, en la misma época del año o bien en otras diferentes? ¿En qué son semejantes? ¿En qué son distintos?

- Finalizada nuestra discusión, expondremos ante el resto de la clase aquellos puntos en los que hay acuerdo general y aquellos otros en los que hay distintas opiniones. Comprobaremos qué han opinado los otros grupos.

Con esta propuesta que acabamos de exponer a modo de ejemplo no hemos querido señalar un único camino para la introducción de los supuestos del análisis crítico del discurso, de los géneros discursivos y de la literacidad crítica en el trabajo de comprensión auditiva; hemos querido, simplemente, mostrar cómo es posible ampliar la perspectiva de nuestra intervención didáctica incorporando nuevos elementos derivados de los avances en los estudios sobre el lenguaje, sobre las lenguas y sobre su enseñanza. Estamos seguros de que los lectores tendrán otras muchas ideas y sugerencias alternativas o complementarias a la que nosotros hemos propuesto. Del mismo modo, no es ocioso indicar que esta muestra de posibles aplicaciones prácticas representa únicamente el contenido esencial del trabajo que nosotros proponemos llevar a cabo, pero que 
de ningún modo se presenta en su forma final y definitiva, pues precisa del conjunto de procedimientos concretos, secuenciados y adaptados a la realidad de cada determinado grupo de alumnos, que permitirán a estos realizar estas actividades de forma significativa y provechosa.

\section{B I B LIOGRAFÍA}

Bajtín, M. (1979). El problema de los géneros discursivos. In M. Bajtín, Estética de la creación verbal (248-293). México: Siglo XXI.

Cassany, D. (2006). Tras las lineas. Barcelona: Anagrama.

Cassany, D. (Comp.) (2009). Para ser letrados. Barcelona: Paidós.

Castellà Lidon, J. M. (2004). Oralitat $i$ escriptura. Dues cares de la complexitat del llenguatge. Barcelona: Publicacions de l'Abadia de Montserrat.

Cots, J. M. (2006). Teaching 'with an attitude': critical discourse analysis in EFL teaching, Elt Journal, 60/4, 336-345.

Fairclough, N. (1995). Critical discourse analysis. Harlow: Longman.

Giroux, H. A. (1988). Los profesores como intelectuales. Hacia una pedagogía crítica del aprendizaje. Barcelona: Paidós.

Koch, P. \& Oesterreicher, W. (2007). Lengua hablada en la Romania: español, francés, italiano. Madrid: Gredos.

Mclaren, P. \& Kincheloe, J. L. (Eds.) (2008). Pedagogía crítica. De qué hablamos, dónde estamos. Barcelona: Graó.

Martín Peris, E. (Dir.) et al. (2008). Diccionario de términos clave de ele. Madrid: Sgel.

Swales, J. M. (1990). Genre analysis. English in academic and research settings. Cambridge: Cambridge University Press.

Van Dijk, T. A. (1999). Ideología. Barcelona: Geedisa.

Van Lier, 1. (1996). Interaction in the language curriculum: awareness, autonomy and authenticity. Londres: Longman. 